\title{
BMJ Global Health Health system governance: welcoming the reboot
}

\author{
Bruno Meessen
}

To cite: Meessen B. Health system governance: welcoming the reboot. BMJ Global Health 2020;5:e002404. doi:10.1136/ bmjgh-2020-002404

Handling editor Seye Abimbola

Received 14 February 2020

Revised 15 June 2020

Accepted 10 July 2020

\section{SLinked}

- http://dx.doi.org/10.1136/ bmjgh-2020-002533

- http://dx.doi.org/10.1136/ bmjgh-2020-003598

Check for updates

C) Author(s) (or their employer(s)) 2020. Re-use permitted under CC BY-NC. No commercial re-use. See rights and permissions. Published by BMJ.

Collective Horizon, Lier, Belgium

Correspondence to

Bruno Meessen;

brunomeessen@outlook.com

\section{INTRODUCTION}

Though a rather recent concept, governance is as old as humanity. Over the last two decades, governance has received a lot of attention from the global health community. The governance lens has been applied to, among others, health, ${ }^{1}$ health systems, ${ }^{2}$ health system strengthening, ${ }^{3}$ health system resilience, ${ }^{4}$ primary healthcare ${ }^{5}$ and hospitals. ${ }^{6}$ Substantial knowledge and understanding have been accumulated in the process. Yet, recent reviews of frameworks have also reported a certain conceptual confusion and lack of progress with the empirical agenda. ${ }^{2}$ No framework has managed to impose itself so far.

Is the health system governance research programme experiencing a stalemate? We don't think so. Recent contributions indicate that a conceptual reboot is on its way. A number of researchers are moving away from the government-centred perspective to an understanding of governance as the organisation by human beings of their collective action. The main goal of this paper is to make the case for this extended approach to governance and to explore its implications, both for research and action. The first section consists in a quick summary on the emergence and development of the concept of health system governance. In the second section, a formalised expression of the new approach to governance is sketched; at its centre is the choice set of actions available to groups of individuals. We use the COVID-19 pandemic, one of the biggest collective action problems faced in the history of humanity, to illustrate our point. In the third section, we explore some key benefits attached to the collective agency approach. The paper ends with some suggestions of ways to move forward.

\section{HEALTH SYSTEM GOVERNANCE AS AN EVOLVING DOMAIN OF INTEREST}

In the field of international development, the mainstream view that governance is a determinant of development outcomes follows

\section{Summary box}

The literature on health system governance is growing. Alternative frameworks have been proposed, but none has really imposed itself so far. The empirical agenda is progressing slowly.

- There is a turning point among recent publications: a move away from a government-centred perspective of governance to a broader understanding of governance as the people's organisation of their collective action.

- In this paper, we argue that what matters is the choice set of actions that groups of individuals can undertake, that is, their collective agency.

- The focus on collective agency broadens the perspective for action: the governance of the health system is not only about the ministry of health doing well certain things, it is about groups of individuals being able to organise their collective action, through the state, but also through other mechanisms.

- The collective agency approach opens avenues for research. For example, governance is both an explanatory and an outcome variable. A governance intervention (explanatory variable) may be effective to improve some health outcomes, but also disempower collective action for some groups of the population (outcome variable).

decades of work developed by the World Bank. ${ }^{78}$ Two WHO reports have been pivotal in establishing a similar view for health systems: the World Health Report $2000^{9}$ and, 7 years later, the report entitled 'Everybody's business: strengthening health systems to improve health outcomes'. ${ }^{10}$

The core contribution of the World Health Report 2000 was to put forward a proposition on how performance of health systems should be conceptualised and measured. Its definition of health system performance focused on outcomes which can be attributed to health interventions. The report also looked at determinants of performance. A whole chapter was dedicated to the concept of stewardship, understood as the central responsibility of the government for the overall performance of a country's health system. 
By the publication of the 2007 report, the concept of stewardship had evolved to 'governance and leadership'. The term 'governance' better captures the fact that health systems are increasingly complex and that in its steering of the health system, a ministry of health has to coordinate with a large set of actors and also to be accountable. The very title of the report acknowledges that health systems are fundamentally collective action problems. However, in subsequent WHO documents, the distinction between governance and leadership was dropped and many contributors to the field fell back on a ministry of health-centred understanding of governance (see reference 11).

The biggest challenge with governance as a concept is probably that it seems to elude measurement. The dominant approach to solve this problem has been to mimic the World Bank's approach of state governance and define dimensions. This has led to a proliferation of frameworks. ${ }^{2}{ }^{12} 13$ In a report for the European Health System Observatory in which they compared existing 'frameworks', Greer et al concluded that such frameworks were long, normative and arbitrary lists of dimensions or items, ${ }^{14}$ and noted that the power of these frameworks to help improve policies still had to be demonstrated. Indeed, most have limited empirical validation. ${ }^{15}$

This highlights the main limitation with the 'good governance' approach: normative choices (defining how things should be) take a central role in determining both the empirical and the policy agenda. Normative orientations are probably inevitable in this field, the problem is that they are rarely cast with sufficient exposure of the values and interests underlying them. This exposes formalisation and subsequent empirical research to arbitrariness or even bias, as authors may be promoting their view of the world or the one that legitimates the theory of change implemented by their agency. Because of their constituencies, agencies may be tempted to promote specific governance mechanisms or downplay dimensions that may arouse hostility from some policy actors.

Recently, several authors have tried to lay down firmer foundations to the governance agenda.

For Siddiqi et al, 'governance comprises the complex mechanisms, processes and institutions through which citizens and groups articulate their interests, mediate their differences and exercise their legal rights and obligations. ${ }^{13}$ In 2014, Abimbola et al explored the lessons from the common-pool resources literature to enlighten collective action for primary healthcare. ${ }^{5}$ To our knowledge, this was the first time that the health system governance literature was connecting with the pioneering work of Elinor Ostrom. If anyone has studied collective action and reflected on how to move from a positivist programme to more prescriptive messages, it is Ostrom. ${ }^{16}$ In 2017, in a review of the literature, Abimbola et al pointed to the shortcomings of the government-centred approach and made the point for a more comprehensive approach to governance and its underlying institutional arrangements. ${ }^{17}$ The same year, Fryatt $e t$ al also came with a more comprehensive approach of governance ${ }^{18}$-it is also marked by their adoption of a non-normative definition of governance-'how societies make and implement collective decisions'. The same year, Pyone et al took a similar approach: 'Governance is defined as the rules (both formal and informal) for collective action and decision making in a system with diverse players and organisations while no formal control mechanism can dictate the relationship among those players and organisations. ${ }^{2}$ Adopting such broad and less normative definitions reduces the risk of excluding certain variables from the scope of analysis.

With this new view, governance can be summarised as the organisation by human beings of their collective action.

We characterise it as a 'reboot' because the focus of the health system governance agenda shifts from the government to the people. Governance of the health system is not just about the ministry of health doing certain things well, it is not even about the ministry of health collaborating with other actors, it is about groups of individuals being able to organise their collective action, also through the state, but not exclusively. In the next section, we propose a formalisation of this new perspective.

\section{FORMALISING GOVERNANCE AS THE ORGANISATION OF OUR COLLECTIVE ACTION}

By adopting the extended formulation of governance, we de facto lose our analytical 'anchor': the organisation. As far as health systems are concerned, no longer can our thinking and analysis be organised around the coordination functions played by the ministry of health. What would then be the new variables of interest?

Our proposition is to organise the analysis around four main sets of variables: (1) the set of collective action problems to solve (let us call it $P$ ) (2) the group of individuals facing this $P(G),(3)$ the set of possible actions $(A)$ that members of $G$ can take at a time $t$ in order to handle $P$ and (4) the conditions $(C)$ determining the choice set $A$.

A collective action problem can be defined as any problem whose solution requires some coordination between potentially benefiting individuals. It can be of various natures: a pandemic to contain, child mortality and the need to reduce it, the performance of a specific hospital.

$G$ can be any grouping of persons of relevance: investors, local community, the medical profession, a nation, the world population. For sure, it is not limited to civil servants working for the ministry of health. $P$ and $G$ are closely linked. The staff of a hospital $(G)$ will be busy with solving a large set of problems: availability of services, organisation of work, quality of care, management of interpersonal conflicts.

Many collective action problems require coordination at the level of different Gs. As a pandemic, COVID-19 requires action at the global level (eg, under the leadership of WHO, the International Monetary Fund, etc), 
but also at the national and community levels. Obviously, a multitude of $G$ s creates coordination issues: different groups have diverse interests and sometimes conflicting interests (cf. Siddiqi et al's definition). Governance is a lot about overcoming such tensions, including, but not exclusively, through mechanisms such as governments.

We propose to put the collective agency held by the group, the choice set $A$, at the centre of the analysis. It can include actions of very different natures. Some actions are generic (eg, stating the problem, agreeing on common goals, adopting rules), others are specific to the problem. COVID-19 can be addressed by closing borders, testing, restricting movement, forbidding social gatherings, treatment. An action belongs to $A$ if it is really feasible by $G$.

The set of possible actions $A$ is itself determined by a set of conditions $(C)$ : the size and composition of $G$, the nature, quantity and distribution of resources (including information and trust) endowed by its members, their preferences, organisations (eg, the ministry of health) and other institutional arrangements in place, as well as external factors such as available technology or security. We do not doubt that future work will generate a more granular view of these conditions and their inter-relationships.

\section{STRENGTHS OF THE APPROACH}

Adopting a collective agency approach to governance has benefits on at least three levels.

\section{More space for less oriented research}

It creates space for theoretical and empirical research independent from normative preferences. It allows (1) description of the different sets of interest (P, G, C, A) at different periods of time; (2) the study of how sets and variables related to each other; (3) the study of how sets and variables are determined across time (historical studies, path dependency); (4) the linking of all these variables to other variables of interest. All these aspects can be investigated, in a neutral manner, without some prejudices on some standards of 'good governance'. This opens new territories for health system governance researchers.

For example, some researchers may want to study how the actual collective agency of a group is also a result of history. Indeed, the capacity of a group to develop health interventions may be partly determined by earlier collective events. Good examples of such phenomena are provided by the recent stream of work establishing a link between slave trade or colonial history with trust and capacity to implement collective action in some regions of Africa. ${ }^{19}{ }^{20}$ COVID-19 reveals that this can also play the other way round. In South Korea, the painful experience with the Middle East respiratory syndromerelated coronavirus outbreak in 2015 generated a lot of learning which expanded the set of actions available for the national response to COVID-19. ${ }^{21}$
Other analysts may want to reorganise the 'order' of the variables. For the last 20 years, we have looked at governance as a 'building block' contributing to health system performance, the latter being measured in terms of health, responsiveness, financial protection outcomes. By equating governance with collective agency, we can, at last, conceptually handle the fact that our collective agency may also be impacted by health policies-that is, be an outcome variable. With COVID-19, we have seen how health policies may affect our individual and collective rights. Some watchdogs are even worried about long-lasting regressions in terms of civic rights. This new perspective could lead to a better recognition of the contribution of health systems to broader political goals (eg, consolidation of the social contract).

\section{New insights thanks to a reorientation of the attention}

By moving the centre of gravity of the analysis (from the ministry of health to our collective agency), the research programme undergoes a double shift which will generate new insights.

The first shift is that we now take a neutral approach toward coordination mechanisms. Ministries of health, rightly, receive a lot of attention. But let us keep in mind that they are quite modern institutions. Our proposition is compatible with the study of institutions organising the practice of medicine in Ancient Greece or during the Islamic Golden Age, for instance. This is also a reminder that even in our societies, a ministry of health is just one coordination mechanism among others. As stressed by Pyone $e t$ al s definition, it is the whole nexus of institutions that matters.

Again, COVID-19 has shown the need to broaden the scope of attention. We have seen how some resources critical for a performing health system (eg, personal protective equipment, test reagents or medicines) are nowadays more governed by global markets than by ministries of health. We have witnessed the spread of conspiracy theories on social media and the subsequent erosion of trust in health authorities. Understanding better other coordination mechanisms (eg, social norms, judicial system, the market, social media) seems a prerequisite before calling to an authority for implementing any corrective measure.

The second shift is a repositioning of institutional arrangements in the analysis. We do not deny that there is great convenience in anchoring governance analyses on organisations. Institutions are key for collective actionthey assign rights and thus reduce uncertainty and coordination costs. ${ }^{22}$ As an organisation, a ministry of health constitutes a stable platform. It can issue policies, which are themselves malleable institutions. Still, organisations and institutions are just instruments. ${ }^{23}$ What ultimately matters to people is the set of actions at their disposal to solve their problems. As analysts we should not forget that this set is determined by more conditions than just institutions. A crucial condition is power. Integrating it into the analysis requires going beyond the mere observation that institutions are in place. The right to strike has 
its intrinsic value, but the impact of a strike will depend on how it disrupts the economy and thus empowers the unions in the negotiation. Another key factor is trust. Low trust in organisations limits options. The COVID-19 crisis has provided examples of nations whose response has been constrained by the growing distrust in the leadership.

\section{Better foundations for normative questions}

The collective agency proposition also allows a more opened discussion about what 'good governance' might be.

It provides a ranking approach which does not bring straight on the preferences of the authors for, for example, a too specific governance modality. Indeed, it gives us probably the least normative ranking criterion possible: for given $G$ and $P$, it is correct to say that conditions $C_{1}$ are superior to conditions $C_{2}$, if $A_{2}$ is larger than $A_{1}$. This is not trivial. For instance, from the perspective of a local community $(G)$, a legal system $\left(G_{1}\right)$ allowing to set up a community health association is superior to a system $\left(C_{2}\right)$ which does not permits that. From the perspective of investors, entrepreneurs or consumers, a social system guaranteeing the rule of law and respect of contracts is also superior to one which does not guarantee such conditions. Of course, a choice set $A$ will rarely dominate all the others and more elaborate criteria will be needed to decide on the inescapable trade-offs. This approach will meet its own limitations, but at least, it will lay bare the normative issues encompassed by the health system governance agenda.

Such an approach valuing 'real rights for collective action' is not without firm moral foundations. It is aligned with the concept of primary goods put forward by Rawls ${ }^{24}$ or the concept of capabilities developed by Nussbaum nd Sen. ${ }^{25}$ Obviously, operationalisation will require to list collective capabilities of importance and establish rules for fair treatment of different groups. We believe this could be done in generic terms (eg, capability for members to appoint a representative to the governing body of the group), but also be tailored to the $G, A$ and $P$ of interest.

\section{WAYS FORWARD}

Over these last years, a new view on health system governance has been emerging. A growing number of authors proposed to take collective action as the central issue. We think it is a healthy development, as it will allow to better disentangle the empirical, normative and prescriptive agendas. Frameworks and concepts are themselves a source of power and influence; the conceptualisation of governance is, by essence, an area where contributors should be vigilant about their positionality.

Our message is not that past research and policy guidance should be wiped out. Conceptual and empirical efforts dedicated to identifying dimensions of interest (transparency, accountability, etc) and supportive institutional mechanisms remain very valuable. ${ }^{26} 27$ In the end, governments formally take on much of the responsibility for governance; reminding them their duties towards their citizens, especially for 'common goods for health', ${ }^{28}$ should remain a central task of multilateral agencies. Our point is that this must be embedded in a broader perspective. Today, we are far from being conceptually and methodologically equipped to capture the actual rights of the groups of individuals having a stake in health systems. Collective agency should be our new conceptual, empirical and prescriptive horizon. We hope that this paper is a useful step in this direction.

The collective agency approach to health system governance surely raises its own challenges. Its value will depend on how useful it proves when employed in empirical research, reflection and action. It encompasses a risk of misuse, for instance, to legitimate more privatisation, ill-conceived decentralisation, societal fragmentation or the unchecked growth of digital giants. Time will tell whether it leads to real progress for people, especially the most vulnerable.

At short term, we must be ready to address heads-on some possible tensions, for instance, when a policy is effective to improve some health outcomes but also disempower groups of the population. Governance is both an explanatory and an outcome variable for health systems. Some of the collective capabilities to protect or to expand may include some sensitive issues (eg, capability to associate or to access reliable information, including through whistle blowers), but there is no escape: excluding them is analytically wrong.

We hope that with the collective agency approach, the global health community will manage to get the issue of governance taking off, both as a field of study and an area of intervention. The COVID-19 crisis indicates that it should happen now.

Acknowledgements The paper benefited a lot from the critical comments provided by the journal's three anonymous reviewers and Dheepa Rajan. I am also grateful to Jean-Benoit Falisse, who helped me with the revision of the paper.

Contributors All contributions by BM.

Funding The authors have not declared a specific grant for this research from any funding agency in the public, commercial or not-for-profit sectors.

Competing interests None declared.

Patient consent for publication Not required.

Provenance and peer review Not commissioned; externally peer reviewed.

Data availability statement All data relevant to the study are included in the article or uploaded as supplementary information.

Open access This is an open access article distributed in accordance with the Creative Commons Attribution Non Commercial (CC BY-NC 4.0) license, which permits others to distribute, remix, adapt, build upon this work noncommercially, and license their derivative works on different terms, provided the original work is properly cited, appropriate credit is given, any changes made indicated, and the use is non-commercial. See: http://creativecommons.org/ licenses/by-nc/4.0/.

ORCID iD

Bruno Meessen http://orcid.org/0000-0002-0359-8621 


\section{REFERENCES}

1 Kickbusch I, Gleicher D. Governance for health in the 21st century. Copenhagen: WHO, 2012.

2 Pyone $\mathrm{T}$, Smith $\mathrm{H}$, van den Broek N. Frameworks to assess health systems governance: a systematic review. Health Policy Plan 2017;32:710-22.

3 Brinkerhoff DW, Bossert TJ. Health governance: principal-agent linkages and health system strengthening. Health Policy Plan 2014;29:685-93.

4 Blanchet K, Nam SL, Ramalingam B, et al. Governance and capacity to manage resilience of health systems: towards a new conceptual framework. Int J Health Policy Manag 2017;6:431-5.

5 Abimbola S, Negin J, Jan S, et al. Towards people-centred health systems: a multi-level framework for analysing primary health care governance in low- and middle-income countries. Health Policy Plan 2014;29:ii29-39.

6 Duran A, Saltman R, Dubois H. A framework for assessing hospital governance. In: Governing public hospitals: reform strategies and the movement towards institutional autonomy. Copenhagen: WHO, 2011: 35-54.

7 World Bank. World development report 1997: the state in a changing world. Washington: World Bank, 1997.

8 Kaufmann D, Kraay A, Zoido-Lobaton P. Governance matters. Washington,DC: World Bank, 1999.

9 WHO. The world health report 2000. Health systems: improving performance. Geneva WHO; 2000.

10 WHO. Everybody's business: strengthening health systems to improve health outcomes: WHO's framework for action. Geneva: WHO, 2007

11 WHO. Monitoring the building blocks of health systems: a handbook of indicators and their measurement strategies. Geneva, 2010.

12 Barbazza E, Tello JE. A review of health governance: definitions, dimensions and tools to govern. Health Policy 2014;116:1-11.

13 Siddiqi S, Masud TI, Nishtar S, et al. Framework for assessing governance of the health system in developing countries: gateway to good governance. Health Policy 2009;90:13-25.

14 Greer SL, Wismar M, Figueras J, et al. Governance: a framework. In: Strengthening health sysstem governance: better policies, stronger performance. Maidenhead: MC Graw Hill education open university press, 2020: 27-56.

15 Mikkelsen-Lopez I, Wyss K, de Savigny D, SD de. An approach to addressing governance from a health system framework perspective. BMC Int Health Hum Rights 2011;11:13.

16 Ostrom E. Beyond markets and states: polycentric governance of complex economic systems. Am Econ Rev 2010;2010:641-72.

17 Abimbola S, Negin J, Martiniuk AL, et al. Institutional analysis of health system governance. Health Policy Plan 2017;32:1337-44.

18 Fryatt R, Bennett S, Soucat A. Health sector governance: should we be investing more? BMJ Glob Health 2017;2:e000343.

19 Nunn N, Wantchekon L. The slave trade and the origins of mistrust in Africa. Am Econ Rev 2011;101:3221-52.

20 Lowes S, Concessions ME. Violence and indirect rule: evidence from the Congo free state, 2018. Available: https://scholar.harvard. edu/slowes/publications/blood-rubberhttps://scholar.harvard.edu/ slowes/publications/blood-rubber [Accessed 1 Feb 2020]

21 Oh J, Lee J-K, Schwarz D, et al. National response to COVID-19 in the Republic of Korea and lessons learned for other countries. Health Syst Reform 2020;6:e-1753464.

22 North D. Institutions, institutional change and economic performance. Cambridge: Cambridge University Press, 1990.

23 Milgrom P. Economics, organization and management. Englewood Cliffs: Prentice-Hall, 1992.

24 Rawls J. A theory of justice. Oxford: Oxford University Press, 1973.

25 Nussbaum MC, Sen A. The quality of life. Oxford: Clarendon Press, 1993.

26 Savedoff WD, Smith PC. Measuring governance: accountability, management and research. In: Strengthening health system governance: better policies, stronger performance. Berkshire: open university press, 2016: 85-104.

27 Lillvis DF, Greer SL. Strategies for policy success: achieving 'good' governance. In: Strengthening health system governance: better policies, stronger performance. Berkshire: Open University Press, 2016.

28 Soucat A. Financing common goods for health: fundamental for health, the foundation for UHC. Health Syst Reform 2019;5:263-7. 